\title{
Göğüs X-Ray görüntülerinin AlexNet tabanlı sınıflandırılması
}

\author{
AlexNet-based classification of chest X-Ray images \\ Kubilay Muhammed SÜNNETCI ${ }^{* 1,2}$ iD , Ahmet ALKAN² iD, Edanur TAR ${ }^{3}$ iD \\ ${ }^{1}$ Department of Electrical and Electronics Engineering, Osmaniye Korkut Ata University, Osmaniye, Turkey \\ ${ }^{2}$ Department of Electrical and Electronics Engineering, Kahramanmaraş Sütçü Imam University, Kahramanmaraş, \\ Turkey \\ ${ }^{3}$ Department of Nursing, Osmaniye Korkut Ata University, Osmaniye, Turkey \\ (kubilaysunnetci@osmaniye.edu.tr, aalkan@ksu.edu.tr, edanurtar@osmaniye.edu.tr)
}

Received: Aug,.31, $2021 \quad$ Accepted: Sep.26, $2021 \quad$ Published: Oct.20, 2021

Özetçe - COVID-19 salgını Aralık 2019'da ilk kez ortaya çıkmış ve o zamandan beri dünyayı etkisi altına almaktadır. Gün geçtikçe dünyada COVID-19 hasta sayısı hızla artmaktadır ve bu hastalığın teşhisinin, hastalık tedavi süreci için önemli olduğu bilinmektedir. COVID-19 hastalığının teşhisinde klinik yardımcı olan göğ̈̈s X-Ray görüntüleri yaygın olarak kullanılmaktadır. Bu çalışmada, uzmanların iş yükünü azaltmak amacıyla, bu görüntüler kullanılarak makine öğrenmesi tabanlı modeller geliştirilmiştir. Çalışmada kullanılan veri setinde toplam 137 COVID-19, 90 normal ve 90 pnömoni kişilerden alınan görüntüler bulunmaktadır. Burada, AlexNet derin öğrenme mimarisi kullanılarak her görüntü için 1000 görüntü özelliği çıkartılmıştır. Sonrasında, bu görüntü özellikleri kullanılarak çalışmada kullanılan sınıflandırıcılar eğitilmiştir. Sonuçlardan, en başarılı sınıflandırıcı olan kübik destek vektör makinesi (Cubic Support Vector Machine, Cubic SVM) sınıflandırıcısının Doğruluk (\%), Duyarlık (\%), Özgüllük (\%), Kesinlik (\%), F skoru (\%) ve Matthews Korelasyon Katsayıs1 (Matthews Correlation Coefficient, MCC) değerlerinin sirasiyla 95.27, 94.95, 97.76, 94.65, 94.79 ve 0.9250'ye eşit olduğu görülmüştür.

Anahtar Kelimeler: COVID-19, özellik çıkartma, derin öğrenme, AlexNet, makine öğrenmesi, hastalık teşhisi

\begin{abstract}
COVID-19 pandemic first broke out in December 2019 and has been affecting the world ever since. The number of COVID-19 patients is increasing rapidly in the world day by day, and it is known that the diagnosis of this disease is important for disease treatment. Chest $\mathrm{X}$-ray images that are clinical adjuncts are widely used in the diagnosis of COVID-19 disease. In the study, machine learningbased models are developed using these images to reduce the workload of expert. In the data set used in the study, there are images obtained from a total of 137 COVID-19, 90 normal, and 90 pneumonia subjects. Here, 1000 image features are extracted for each image using AlexNet deep learning architecture. Afterward, the classifiers used in the study are trained using these image features. From the results, Accuracy (\%), Sensitivity (\%), Specificity (\%), Precision (\%), F1 score (\%), and Matthews Correlation Coefficient (Matthews Correlation Coefficient, MCC) values of Cubic SVM that is the most successful classifier are equal to $95.27,94.95,97.76,94.65,94.79$, and 0.9250 , respectively.
\end{abstract}

Keywords: COVID-19, feature extraction, deep learning, AlexNet, machine learning, disease diagnosis 


\section{Giriş}

SARS-CoV-2 virüsünün neden olduğu "Yeni Koronavirüs Hastalığı" (COVID-19)'na ilk olarak 2019 yılında Çin'in Wuhan kentinde rastlanmıştır. Hızla tüm dünyaya yayılması ile DSÖ tarafından Mart 2020'de pandemi ilan edilmiştir (DSÖ, 2021). Damlacıklar ve yakın temas ile yayılım gösteren SARS-CoV-2 virüsü ile enfekte olan bireylerde belirtiler kişiden kişiye farkl1lık gösterebilmektedir. S1klıkla görülen semptomlar $38{ }^{\circ} \mathrm{C}$ 'nin üzerinde ateş, yorgunluk, kuru öksürük iken ağrı, titreme, burun tıkanıklığı, soğuk algınlığı, boğaz ağrısı, nefes darlığı, sindirim sistemi bozuklukları, koku ve tat kaybı gibi belirtiler de ortaya çıkabilmektedir. Enfekte olan bireylerin çoğu hafif ve orta şiddetli semptomlar verirken enfeksiyon şiddetli solunum yetmezliği ve ölümle de sonuçlanabilmektedir (Tar ve Küçükoğlu, 2021; Ludvigsson, 2020; Hadi vd., 2020). Bulaş1cılığ1 oldukça yüksek olan bu hastalık, Ağustos 2021 tarihi itibariyle yaklaşık 202 milyon kişiyi enfekte etmiş ve 4 milyon kişinin ölümüne yol açmıştır (Wolrdometer, 2021). Virüsün daha fazla bireye yayılımını önlemek için enfekte olmuş bireylerin tespit edilmesi ve izolasyona alınması oldukça önemlidir. Nazofarengial sürüntü ile yapılan "Ters tr anskripsiyon-kantitatif polimeraz zincir reaksiyonu" (RT-qPCR) dünya çapında COVID-19'un teşhisinde kullanılan altın standart yöntemdir. Ancak karmaşık laboratuvar ekipmanı ve kalifiye personel ihtiyacı nedeniyle RT-qPCR'nin gerçekleştirilmesi merkezi laboratuvarlarla sınırlıdır. Ayrıca bazen yanlış negatif veya belirsiz sonuçlar verebilmektedir. Bu nedenle yanılmaların önlenmesi amacıyla RT-qPCR test sonuçları, semptomlar ve radyolojik yöntemler ile değerlendirilmelidir (Palaz vd., 2021; Zimmermann ve Curtis, 2020).

Radyolojik yöntemlerden göğüs X-Ray görüntülerinin kullanımı COVID-19'un neden olduğu pnömoninin tespitinde yol gösterici olurken araştırmalar bunların radyologlar tarafından farklı bakış açıları ile yorumlandığını göstermektedir (Maguolo ve Nanni, 2021; Ai vd., 2020). Bu aşamada makine öğrenmesi ve derin öğrenme teknikleri kullanımının COVID-19'un tespitinde yüksek performans alınabileceğini bildiren çalışmalar mevcuttur (Booth vd., 2021; Jadon, 2021; Kassania vd., 2021; Khuzani vd., 2021; Kwekha-Rashid vd., 2021; Muhammet vd., 2021; Rasheed vd., 2021). Jadon (2021)'un çalışmasında veri büyütme, transfer öğrenme ve denetimsiz öğrenme gibi birkaç adımlı öğrenme yaklaşımı ile temel modelleri kullanarak göğüs X-Ray görüntülerinden COVID-19'un tespitinde $\% 83$ 'ten $\% 96,4$ doğrulukta verimli ve doğru bir derin öğrenme modeli elde edildiği sonucuna ulaşılmıştır. Makine öğrenimi kullanılarak COVID-19 enfeksiyonunda mortalite için prognostik bir model geliştirilen bir diğer çalışmada ise mortalite riski en yüksek olan hastalarda prognostik serum biyobelirteçlerini belirlemek amacıyla SARS-CoV-2 pozitif hastalardan alınan laboratuvar verileri ve mortalite analiz edilmiştir. Ölümün 48 saat öncesinde tahmin edilmesi amacıyla hastanın c-reaktif protein, kan üre azotu, serum kalsiyum, serum albümin ve laktik asit laboratuvar değerleri kullanılarak bir makine öğrenim modeli geliştirilmiştir. Elde edilen destek vektörü makine modelinde, uzatılmış test verilerinde hastanın ölümünü tahmin etmek için \%91 duyarlılık ve \%91 özgüllük (AUC 0.93) tespit edilmiştir (Booth vd., 2021). Kwekha-Rashid ve ark. (2021) COVID-19 ile ilgili araştırmalarda makine öğrenmesi uygulamaları ve algoritmalarının rolünü tespit etmek amacıyla yaptıkları çalışmasında 14 makale incelemiştir. Makine öğreniminin COVID-19 vakalarının değerlendirilmesi ve sınıflandırılmasında önemli rol oynayabileceği ve denetimli öğrenmenin \%92,9 test doğruluğu ile diğer denetimsiz öğrenme algoritmalarından daha iyi sonuçlar verdiği saptanmıştır (Kwekha-Rashid vd., 2021). COVID-19 ve pnömoni tanısı alan hastalar ile normal bireylerin gögüs X-Ray görüntüleri kullanılarak yapılan makine öğrenmesi temelli bir diğer çalışmada ise farklı türde akciğer hastalıklarının sınıflandırılmasında \%94 oranında doğruluğa ulaşılmıştır (Khuzani vd., 2021). Muhammet ve ark. (2021) Meksika'da COVID-19 pozitif ve negatif vakalar için epidemiyoloji etkiketli veri setlerini (RTPCR sonuçları) kullanarak Decision Tree, Logistic Regression, Naive Bayes, Support Vector Machine ve Artificial Neural Network ile COVID-19 enfeksiyonu için denetimli makine öğrenimi modelleri geliştirmiştir. Bu modeler arasında en yüksek doğruluk \%94.99 ile Decision Tree iken en başarılı ikinci sistemin doğruluk oranı \%94.41 ile Logistic Regression sinıflandırıcısıdır (Muhammet vd., 2021). Gögüs X-Ray görüntülerinden makine öğrenimi tabanlı COVID-19 teşhisi için Logistic Regression (LR) ve Convolutional Neural Networks (CNN) yöntemlerinin kullanıldığı farklı bir çalışmada ise LR ve CNN modellerinin pozitif vaka tanımlaması temel bileşen analizi (PCA) olmadan \%95,2-97.6 ve PCA ile \%97,6-100 genel doğruluk gösterdiği saptanmıştır (Rasheed vd, 2021). Kassania ve ark. (2021)'nın makine öğrenimi tabanlı bir yaklaşım ile X-Ray ve Bilgisayarlı Tomografi (BT) görüntülerinde COVID- 
19 tespiti amacıyla yaptıkları çalışmalarında Bagging Tree sınıflandırıcılı DenseNet121 öznitelik çıkarıcının \%99 sınıflandırma doğruluğu ile en iyi performansı elde ettiği ve ikinci en iyi öğrenicinin LightGBM tarafından \%98 doğrulukla eğitilmiş bir ResNet50 özellik çıkarıcının bir çeşidi olduğu tespit edilmiştir.

Bu çalışmada 137 COVID-19, 90 normal ve 90 pnömoni bireylerden alınan toplam 317 göğüs XRay görüntüsü kullanılmıştır. Burada, her bir görüntü için AlexNet derin öğrenme mimarisi kullanılarak fc8 katmanından 1000 görüntü özelliği elde edilmiştir. Elde edilen bu görüntü özellikleri 8-kat çapraz doğrulama tekniği kullanılarak sınıflandırılmıștır. Bu çalışmada, Medium Tree, Bagged Trees Ensemble, Kernel Naive Bayes, Cosine KNN, Linear Discriminant, Quadratic SVM, Linear SVM ve Cubic SVM sınıflandırıcıları kullanılmıştır. Çalışmada kullanılan sınıflandırıcılar sınıflandırma performans metrikleri açısından birbirleriyle karşılaş̧tırılmıştır.

Çalışma şu şekilde organize edilmiştir. Bölüm 2'de kullanılan veri seti açıklanmıştır ve Bölüm 3'te önerilen sistem açıklanmıştır. Burada, kullanılan özellik çıkartma yöntemi, eğitim parametreleri gibi bilgiler verilmektedir. Bölüm 4'te, çalışmada elde edilen deneysel sonuçlar paylaşılmıştır. Son olarak ise, yapılan çalışmanın sonuçları sunulmuştur.

\section{Veri}

Bu bölümde, Kaggle platformundan aldığımız göğüs X-Ray görüntüleri tanıtılmaktadır (Covid-19 Image Dataset, https://www.kaggle.com/pranavraikokte/covid19-image-dataset). Burada, 137 COVID19 pozitif, 90 normal ve 90 pnömoni bireylerden alınan görüntü örnekleri bulunmaktadır. Bu görüntüler JPG, JPEG ve PNG formatındadır.

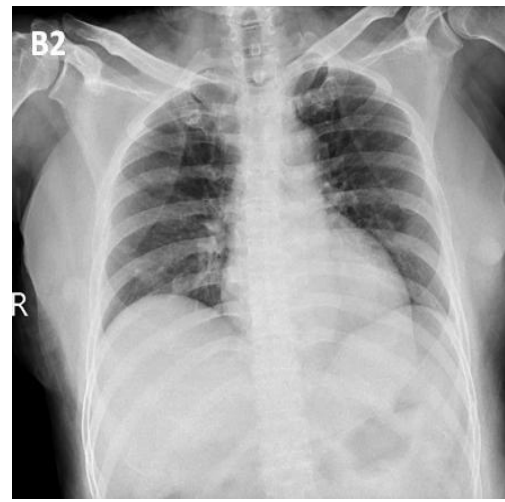

(a)

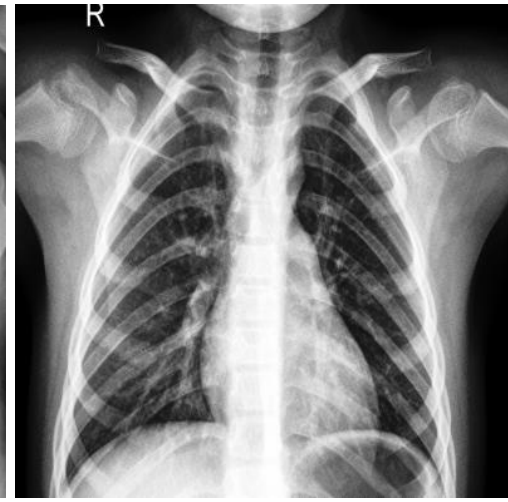

(b)

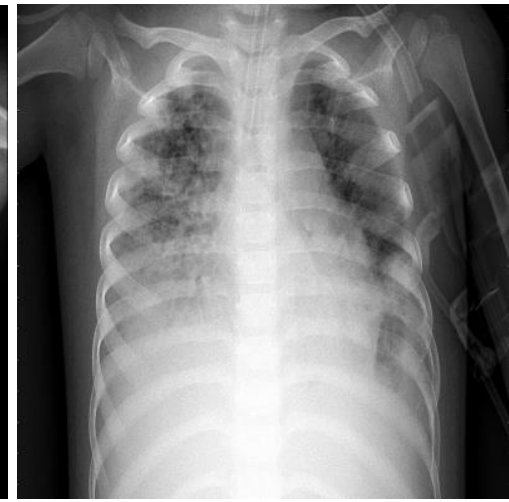

(c)

Şekil 1. Çalışmada kullanılan veri setinde bulunan örnek gögüs X-Ray görüntüleri

a) COVID-19, b) Normal, c) Pnömoni

Şekil 1'de çalışmada kullanılan veri setinde bulunan her bir sınıfa ait bir görüntü örneği bulunmaktadır. Şekil 1.a-c'de sırasıyla COVID-19 pozitif, normal ve pnömoni bireylerden alınmış göğüs X-Ray görüntüleri verilmektedir. Bu noktada, çalışmada kullanılan veri seti için 8-kat çapraz doğrulama kullanılarak sınıflandırıcılar eğitilmektedir.

\section{3. Önerilen Sistem}

Bu çalışmada, 137 COVID-19, 90 Normal ve 90 pnömoni kişiden alınmış olan toplam 317 görüntü kullanılmıştır. Burada, öncelikle veri setinde bulunan görüntülerden görüntü özellikleri AlexNet Derin Öğrenme mimarisine göre çıkarılmıştır. Tam bağlantılı katmanlardan her bir görüntü için 1000 adet 
özellik elde edilmiştir. Sonrasında, elde edilen görüntü özellikleri kullanılarak, Medium Tree, Bagged Trees Ensemble, Kernel Naive Bayes, Cosine K-Nearest Neighbor (KNN), Linear Discriminant, Quadratic SVM, Linear SVM ve Cubic SVM sınıflandırıcıları eğitilmiştir (Alkan ve Günay, 2012; Akben, 2018; Polikar, 2012; Rish, 2001; Guo vd., 2003). Eğitim için 8-kat çapraz doğrulama tekniği kullanılmaktadır. Eğitim aşamasından önce, görüntü özelliklerinin AlexNet mimarisi kullanılarak çıkartılması nedeniyle, Şekil 2'de AlexNet mimarisinin ă̆ katman bilgileri verilmektedir (Siyuan vd., 2019).

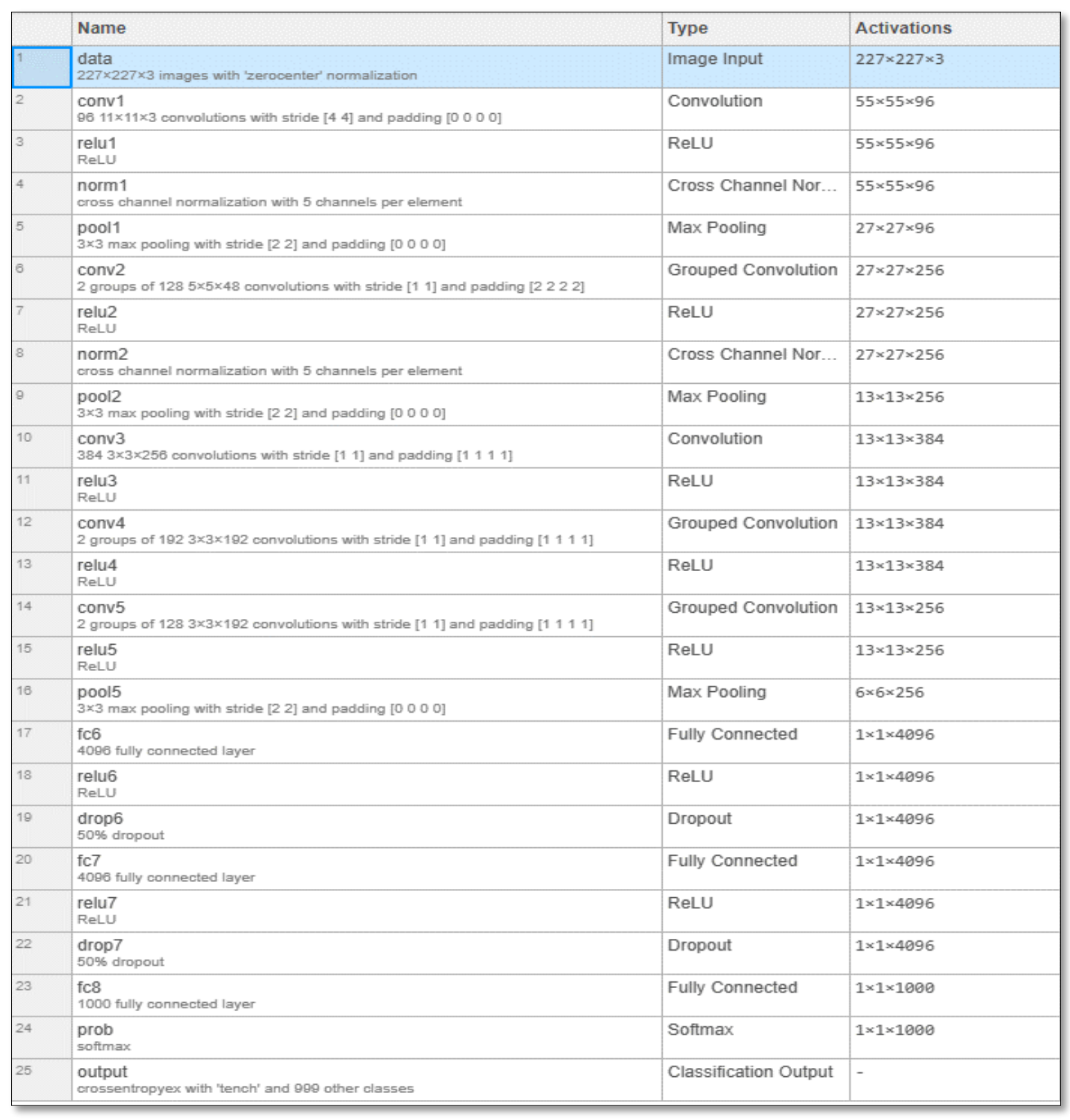

Şekil 2. AlexNet mimarisinin ağ katmanlarının görselleştirilmesi

Şekil 2'de, çalışmada görüntü özelliklerinin çıkartılması için kullanılan AlexNet mimarisi ağ katmanları gösterilmektedir. AlexNet, 8 katman derinliğine sahip bir mimaridir ve 1000 kategoriye kadar sınıflandırma işlemi yapabilir. Şekilde de görüldüğü gibi, $227 * 227 * 3$ görüntüler için kullanılabilen bu mimari toplamda 25 katman içermektedir. Burada, konvolüsyon (Convolution), havuzlama (Pooling), ReLu ve tam bağlantılı katmanların (Fully Connected Layer) bulunduğu görülür (Alex vd, 2012). Ağ mimarisi incelendiğinde, biz 23 numaralı satırda bulunan fc8 katmanından görüntü 
özelliklerini elde etmekteyiz. Şekilden de görüldügü gibi, bu katman sayesinde her bir görüntü için 1000 adet görüntü özelliği çıkartılabilmektedir. Sonrasında, çıkartılan bu görüntü özellikleri kullanılarak çalışmada kullanılacak olan sınıflandırıcılar eğitilebilmektedir. Bu noktada, çalı̧̧mada kullanılan sınıflandırıcılar için elde edilen eğitim parametreleri ve değerlendirme metrikleri Tablo 1'de verilmiştir.

Tablo 1. Çalışmada kullanılan sınıflandırıcılar için eğitim parametreleri ve değerlendirme metrikleri

\begin{tabular}{|c|c|c|c|c|c|}
\hline & $\begin{array}{l}\text { Doğruluk } \\
(\%)\end{array}$ & $\begin{array}{l}\text { Toplam Yanlış } \\
\text { Sinıflandırma }\end{array}$ & $\begin{array}{c}\text { Tahmini Hiz } \\
\sim \text { obs/s }\end{array}$ & $\begin{array}{c}\text { Eğitim } \\
\text { Zaman1 } \\
\text { s }\end{array}$ & Model Tipi \\
\hline $\begin{array}{l}\text { Medium } \\
\text { Tree }\end{array}$ & 80.76 & 61 & 620 & 10.583 & $\begin{array}{c}\text { Maksimum bölme } \\
\text { sayısı:20, Gini çeşitlilik } \\
\text { endeksi }\end{array}$ \\
\hline $\begin{array}{l}\text { Bagged } \\
\text { Trees } \\
\text { Ensemble }\end{array}$ & 90.54 & 30 & 300 & 46.263 & $\begin{array}{c}\text { Maksimum bölme } \\
\text { say1s1:316, Öğrenici } \\
\text { say1s1:30 }\end{array}$ \\
\hline $\begin{array}{c}\text { Kernel } \\
\text { Naïve Bayes }\end{array}$ & 91.17 & 28 & 41 & 123.01 & Kernel tipi: Gaussian \\
\hline Cosine KNN & 91.17 & 28 & 440 & 32.902 & $\begin{array}{l}\text { Komşu sayıs1:10, Mesafe } \\
\text { metriği: Cosine }\end{array}$ \\
\hline $\begin{array}{c}\text { Linear } \\
\text { Discriminant }\end{array}$ & 91.48 & 27 & 570 & 9.7243 & Kovaryans yapısı: Tam \\
\hline $\begin{array}{l}\text { Quadratic } \\
\text { SVM }\end{array}$ & 94.01 & 19 & 430 & 18.488 & $\begin{array}{l}\text { Kernel fonksiyonu: } \\
\text { Quadratic }\end{array}$ \\
\hline Linear SVM & 94.95 & 16 & 390 & 18.2 & $\begin{array}{c}\text { Kernel fonksiyonu: } \\
\text { Linear }\end{array}$ \\
\hline Cubic SVM & 95.27 & 15 & 490 & 22.928 & $\begin{array}{l}\text { Kernel fonksiyonu: } \\
\text { Cubic }\end{array}$ \\
\hline
\end{tabular}

Tablo 1'de, çalışmada kullanılan sınıflandırıcılar için eğitim parametreleri ve bazı değerlendirme metrikleri verilmiştir. Aynı zamanda bu sınıflandırıcılar için, sınıflandırma yöntemlerinde kullanılan model tipleri de Tablo 1'de yer almaktadır. Tablodan, çalışmada kullanılan Medium Tree, Bagged Trees Ensemble, Kernel Naive Bayes, Cosine KNN, Linear Discriminant, Quadratic SVM, Linear SVM ve Cubic SVM sınıflandırıcılarının doğruluklarının sırasıyla \%80.76, \%90.54, \%91.17, \%91.17, \%91.48, \%94.01, \%94.95 ve \%95.27'ye eşit olduğu görülmektedir. Bu nedenle toplam yanlış sınıflandırma ve doğruluk açısından en başarılı sistemin Cubic SVM olduğu anlaşılabilmektedir. Bu sınıflandırıcılar, eğitim zamanı açısından incelendiğinde ise en başarılı sistemlerin sırasıyla Linear Discriminant ve SVM sınıflandırıcılarının olduğu görülmektedir.

\section{Deneysel Sonuçlar}

Bu bölümde, veri dağılım grafiğgi, karmaşıklık matrisleri ve pozitif sınıflar için Receiver Operating Characteristic (ROC) eğrileri verilmektedir. Bu noktada, çalışmada kullanılan sınıflandırıcıların performans metriklerini yorumlayabilmek açısından karmaşıklı matrisleri ve ROC eğrilerinin incelenmesi gerekmektedir. Bu nedenle, karmaşıklık matrisi üç farklı şekilde incelenmektedir (doğru ve hatalı gözlem sayısı, Doğru Pozitif Oranları (True Positive Rates, TPR)-Yanlış Negatif Oranları (False Negative Rates) ve Pozitif Tahmin Değerleri (Positive Predictive Values, PPV)-Yanlış Keşif Oranları 
(False Discovery Rates, FDR)). Benzer şekilde, her sınıf için ROC eğrilerinin altında kalan alan değerleri ve grafikleri de burada verilmektedir.

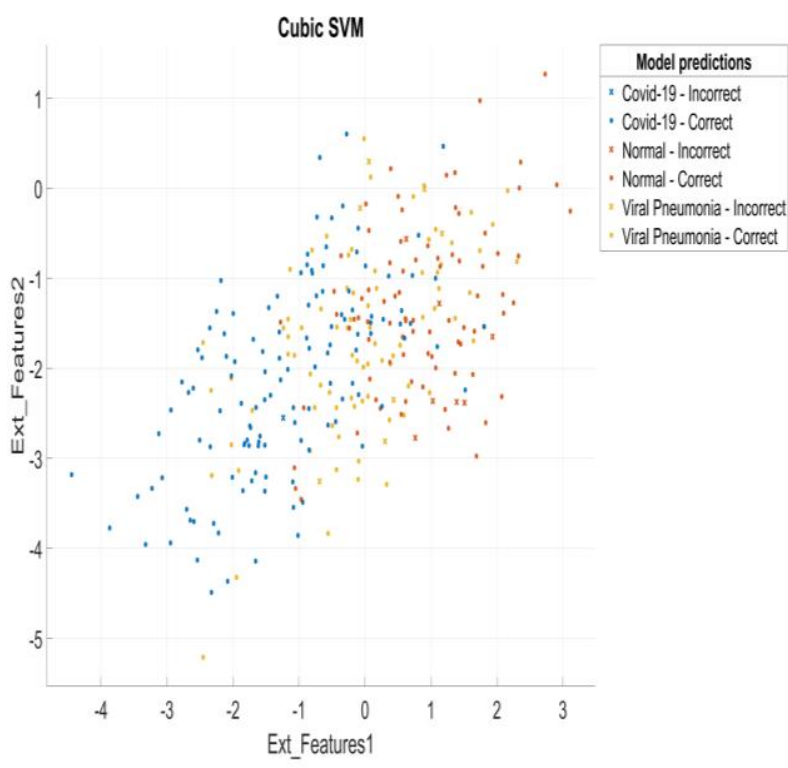

(a)

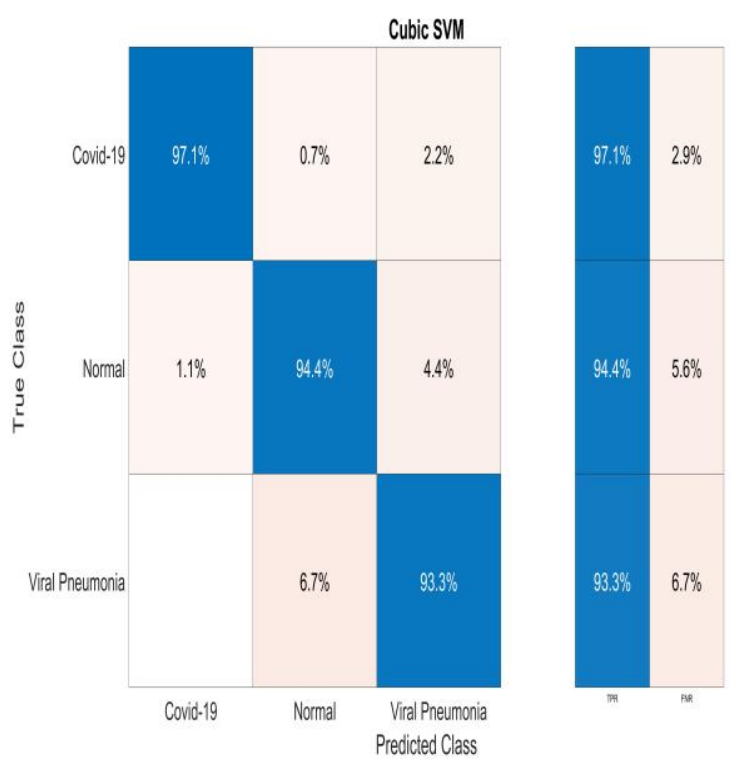

(c)

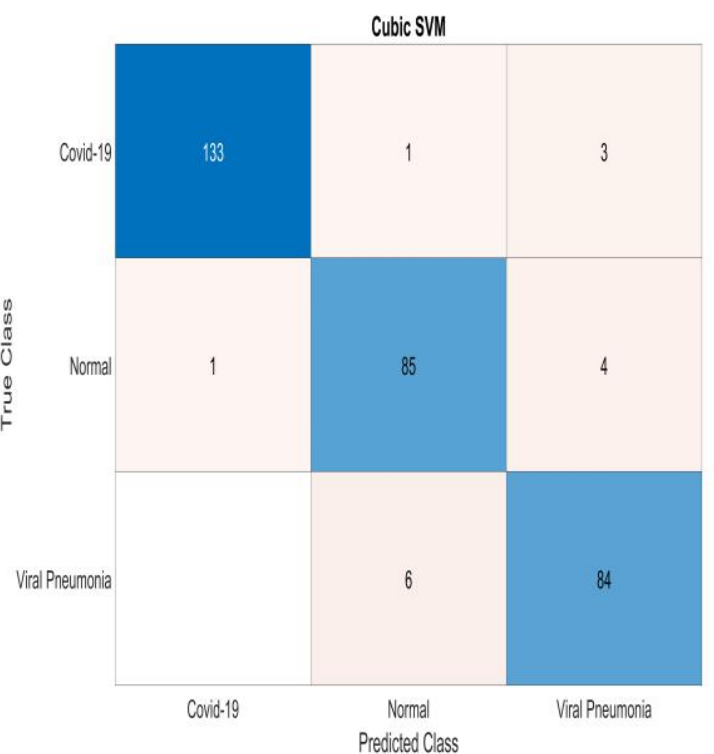

(b)

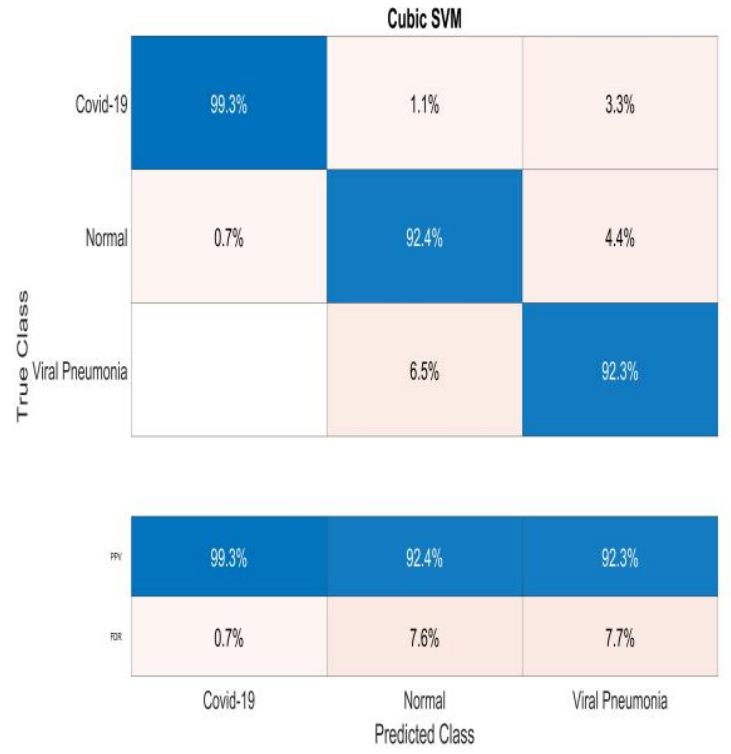

(d)

Şekil 3. En başarılı sınıflandırıcı olan Cubic SVM'nin veri dağılım grafiği ve karmaşıklık matrisleri

Şekil 3.a ve 3.b-d'de, çalışmada kullanılan modeller arasından en başarılı olan Cubic SVM sınıflandırıcısının sırasıyla veri dağılım grafiğgi ve karmaşıklık matrisleri gösterilmektedir. Bu noktada, AlexNet mimarisine göre çıkartılan 1000 özelliğin iki tanesi, iki boyutlu olan Şekil 3. a'da gösterilmektedir. Burada, her bir sınıf için doğru veya hatalı olarak belirlenen özellik değerleri görülebilmektedir. Bir diğer taraftan, Şekil 3.b her sınıf için yapılan doğru ve hatalı tahmin sayılarını göstermektedir. Şekil 3.b'ye göre, 137 COVID-19 hastasının 133 tanesi COVID-19 olarak bilinirken, 1 tane tanesi normal ve 3 tanesi de pnömoni olarak tahmin edilmiştir. Benzer şekilde, 90 normal ve 90 pnömoni kişi sırasıyla 1 COVID-19/85 normal/4 pnömoni ve 0 COVID-19/6 normal/84 pnömoni olarak 
tespit edilmiştir. Bu noktada, Cubic SVM sınıflandırıcısının 8-kat çapraz doğrulama kullanarak elde ettiği performans metrikleri incelendiğinde, eğitim ve doğrulama aşamasının başarılı bir şekilde gerçekleştiği anlaşılabilmektedir. Şekil 3.c-d bu sınıflandırıcının sırasıyla TPR-FNR ve PPV-FDR değerlerini göstermektedir. Bu şekillerden COVID-19, normal ve pnömoni kişiler için elde edilen TPR ve PPV değerlerinin sirasıyla \%97.1-\%94.4-\%93.3 ve \%99.3-\%92.4-\%92.3'a eşit olduğu görülebilmektedir. İlaveten, bu sınıflandırıcının bir başka performans metriği incelemesi için aşağıdaki gibi farklı pozitif sınıfların ROC eğrileri verilmiştir.

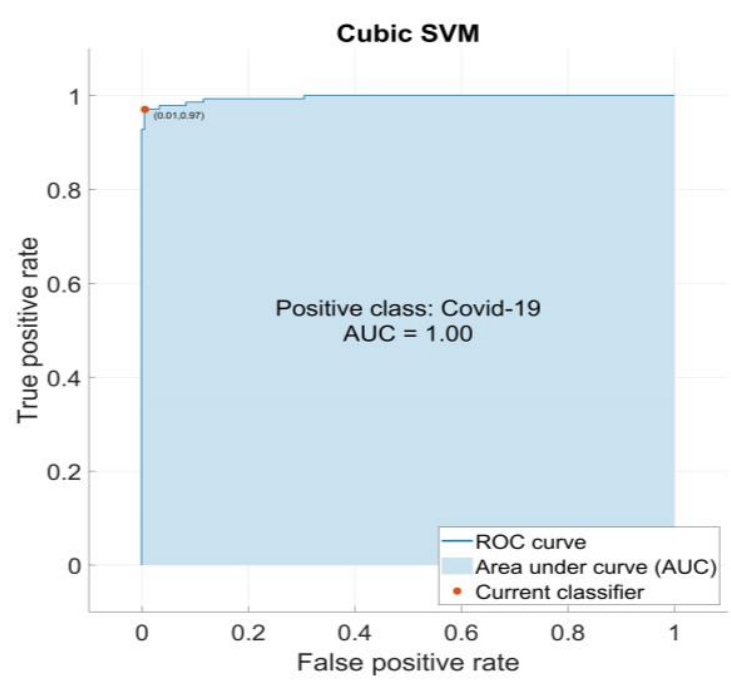

(a)

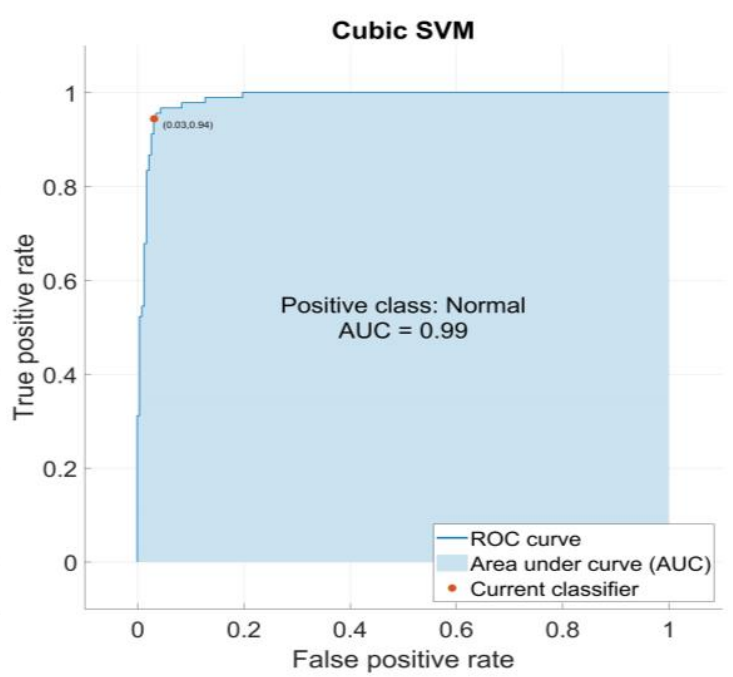

(b)

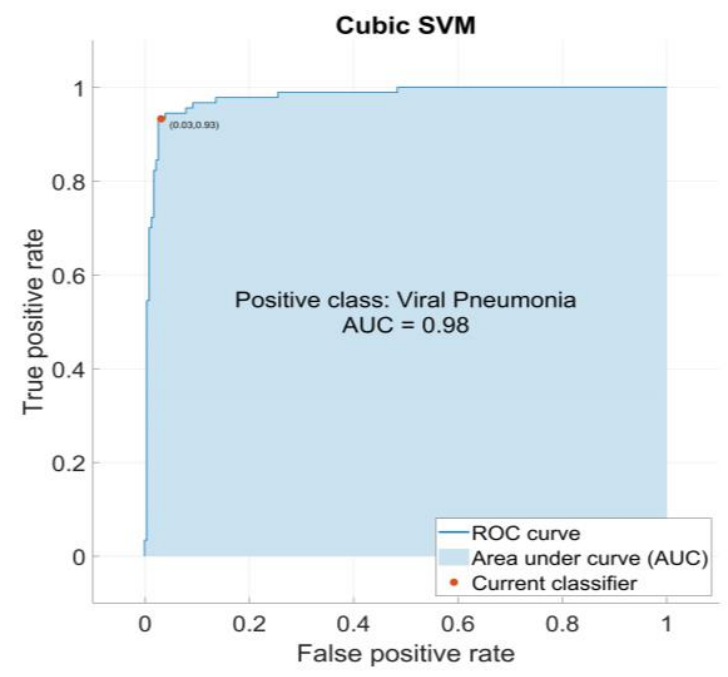

(c)

Şekil 4. En başarılı sınıflandırıcı olan Cubic SVM'nin ROC eğrileri

Şekil 4.a-c'de, Cubic SVM sınıflandırıcısı için pozitif sınıflar sırasıyla COVID-19, normal ve pnömoni olarak çizdirilmiştir. Burada, eğri altında kalan alan (Area Under Curve, AUC) 1'e yaklaştıkça, eğitimin başarılı bir şekilde gerçekleştiği söylenebilmektedir. Bu noktada, Şekil 4.a-c'de verilen şekillerden, COVID-19, normal ve pnömoni pozitif sınıflarının AUC değerlerinin sırasıyla 1, 0.99 ve 0.98'e eşit olduğu görülmektedir. Böylece, çalışmada kullanılan en başarılı sınıflandırıcı olan Cubic SVM'nin en başarılı tespiti COVID-19 sınıfında yapabildiği görülmektedir. 


\section{Sonuçlar}

Bu çalışmada, AlexNet derin öğrenme mimarisi kullanılarak 317 görüntü için görüntü özellikleri çıkartılmaktadır. Bu görüntülerin 137 tanesi COVID-19, 90 tanesi normal ve 90 tanesi de pnömoni kişilerden alınmıştır. Bu görüntülerin özellikleri, AlexNet derin öğrenme mimarisin fc8 katmanından elde edilmektedir. Ayrıca her bir görüntü bir için çıkartılan görüntü özelliği sayısı 1000'e eşittir. Sonrasında çıkartılan bu özellikler kullanılarak, Medium Tree, Bagged Trees Ensemble, Kernel Naive Bayes, Cosine KNN, Linear Discriminant, Quadratic SVM, Linear SVM ve Cubic SVM sınıflandırıcıları eğitilmektedir. Bu noktada, eğitim ve doğrulama seti 8-kat çapraz doğrulama yöntemiyle oluşturulmuştur. Böylece, çalışmada kullanılan bütün sınıflandırıcılar için karmaşıklık matrisleri elde edilebilmektedir. $\mathrm{Bu}$ sinıflandırıcıların karmaşıklık matrislerinden faydalanılarak hesaplanabilen sınıflandırma performans metrikleri Tablo 2'de ki gibi verilmiştir.

Tablo 2. Çalışmada kullanılan sınıflandırıcıların sınıflandırma performans metrikleri

\begin{tabular}{|c|c|c|c|c|c|c|c|c|}
\cline { 2 - 9 } \multicolumn{1}{c|}{} & $\begin{array}{c}\text { Medium } \\
\text { Tree }\end{array}$ & $\begin{array}{c}\text { Bagged } \\
\text { Trees } \\
\text { Ensemble }\end{array}$ & $\begin{array}{c}\text { Kernel } \\
\text { Naïve } \\
\text { Bayes }\end{array}$ & $\begin{array}{c}\text { Cosine } \\
\text { KNN }\end{array}$ & $\begin{array}{c}\text { Linear } \\
\text { Discriminant }\end{array}$ & $\begin{array}{c}\text { Quadratic } \\
\text { SVM }\end{array}$ & $\begin{array}{c}\text { Linear } \\
\text { SVM }\end{array}$ & $\begin{array}{c}\text { Cubic } \\
\text { SVM }\end{array}$ \\
\hline $\begin{array}{c}\text { Doğruluk } \\
(\%)\end{array}$ & 80.76 & 90.54 & 91.17 & 91.17 & 91.48 & 94.01 & 94.95 & $\mathbf{9 5 . 2 7}$ \\
\hline $\begin{array}{c}\text { Hata (\%) } \\
19.24\end{array}$ & 9.46 & 8.83 & 8.83 & 8.52 & 5.99 & 5.05 & $\mathbf{4 . 7 3}$ \\
\hline $\begin{array}{c}\text { Duyarl1lık } \\
(\%)\end{array}$ & 79.44 & 89.52 & 90.39 & 90.14 & 91.14 & 93.73 & 94.58 & $\mathbf{9 4 . 9 5}$ \\
\hline $\begin{array}{c}\text { Özgüllük } \\
(\%)\end{array}$ & 90.54 & 95.29 & 95.66 & 95.62 & 96.00 & 97.17 & 97.61 & $\mathbf{9 7 . 7 6}$ \\
\hline $\begin{array}{c}\text { Kesinlik } \\
(\%)\end{array}$ & 79.44 & 89.86 & 90.40 & 90.61 & 90.54 & 93.28 & 94.35 & $\mathbf{9 4 . 6 5}$ \\
\hline $\begin{array}{c}\mathrm{F}_{1} \text { Skoru } \\
(\%)\end{array}$ & 79.39 & 89.65 & 90.39 & 90.23 & 90.77 & 93.47 & 94.44 & $\mathbf{9 4 . 7 9}$ \\
\hline MCC & 0.6992 & 0.8504 & 0.8606 & 0.8605 & 0.8669 & 0.9058 & 0.9202 & $\mathbf{0 . 9 2 5 0}$ \\
\hline
\end{tabular}

Tablo 2 çalışmada kullanılan tüm sınıflandırıcıların sınıflandırma performans metriklerini göstermektedir. Tablodan, çalışmada kullanılan Medium Tree, Bagged Trees Ensemble, Kernel Naive Bayes, Cosine KNN, Linear Discriminant, Quadratic SVM, Linear SVM ve Cubic SVM sinıflandırıcılarının doğruluklarının sırasıyla \%80.76, \%90.54, \%91.17, \%91.17, \%91.48, \%94.01, $\% 94.95$ ve \%95.27 olduğu görülmektedir. Böylece, doğruluk açısından en başarılı sınıflandırıcının Cubic SVM olduğu görülmektedir. En iyi sınıflandırıcının belirlenmesi hususunda sadece doğruluk metriğinin incelenmesi gereklidir ama yeterli değildir. Tablo incelendiğinde, en başarılı sınıflandırıcı olan Cubic SVM'nin hata (\%), duyarlık (\%), özgüllük (\%), kesinlik (\%), $\mathrm{F}_{1}$ skoru (\%) ve MCC değerlerinin sırasıyla 4.73, 94.95, 97.76, $94.65,94.79$ ve 0.9250 olduğu görülür. Cubic SVM'nin sınıflandırma performans metrikleri diğer sınıflandırıcılarla karşılaştırıldığında, bu sınıflandırıcının diğer sınıflandırıcılardan daha başarılı olduğu görülmektedir.

\section{Kaynakça}

Alkan A, Günay M. (2012) Identification of EMG signals using discriminant analysis and SVM classifier. Expert systems with Applications 39(1):44-47.

Akben SB. (2018) Predicting the success of wart treatment methods using decision tree based fuzzy informative images. Biocybernetics and Biomedical Engineering 38(4): 819-827. 
Ai T, Yang Z, Hou H, Zhan C, Chen C, Lv W, Xia L (2020) Correlation of chest CT and RT-PCR testing for coronavirus disease 2019 (COVID-19) in China: a report of 1014 cases. Radiology 296(2): E32E40.

Booth AL, Abels E, McCaffrey P (2021) Development of a prognostic model for mortality in COVID19 infection using machine learning. Modern Pathology 34(3):522-531.

Dataset (2021) https://www.kaggle.com/pranavraikokte/covid19-image-dataset, COVID-19 Image Dataset, Pranav Raikote.

Dünya Sağl1k Örgütü (WHO) (2021) WHO Announces COVID-19 Outbreak a Pandemic. https://www.euro.who.int/en/health-topics/healthemergencies/coronaviruscovid19/news/news/2020/3/who-announces-covid19-outbreak-a-pandemic. Accessed 07.08.2021

Hadi AG, Kadhom M, Hairunisa N, Yousif E, Mohammed SA (2020) A review on COVID-19: origin, spread, symptoms, treatment, and prevention. Biointerface Research in Applied Chemistry 10(6): 7234-7242.

Guo G, Wang H, Bell D, Bi Y, Greer K. (2003) KNN model-based approach in classification. In OTM Confederated International Conferences" On the Move to Meaningful Internet Systems" Springer, Berlin, Heidelberg. pp.986-996.

Jadon S (2021) COVID-19 detection from scarce chest x-ray image data using few-shot deep learning approach. In Medical Imaging 2021: Imaging Informatics for Healthcare, Research, and Applications 11601:116010X.

Kassania SH, Kassanib PH, Wesolowskic MJ, Schneidera KA, Detersa R (2021) Automatic detection of coronavirus disease (COVID-19) in X-ray and CT images: a machine learning based approach. Biocybernetics and Biomedical Engineering 41(3):867-879.

Khuzani AZ, Heidari M, Shariati SA (2021) COVID-Classifier: An automated machine learning model to assist in the diagnosis of COVID-19 infection in chest x-ray images. Scientific Reports 11(1):1-6.

Krizhevsky A, Sutskever I, Hinton GE. (2012) Imagenet classification with deep convolutional neural networks. Advances in Neural Information Processing Systems 25:1097-1105.

Kwekha-Rashid AS, Abduljabbar HN, Alhayani B (2021) Coronavirus disease (COVID-19) cases analysis using machine-learning applications. Applied Nanoscience 1-13.

Lu S, Lu Z, Zhang YD. (2019) Pathological brain detection based on AlexNet and transfer learning. Journal of Computational Science 30: 41-47.

Ludvigsson JF (2020) Systematic review of COVID-19 in children shows milder cases and a better prognosis than adults. Acta Paediatrica 109(6):1088-1095.

Maguolo G, Nanni L. (2021) A critic evaluation of methods for covid-19 automatic detection from Xray images. Information Fusion 76:1-7.

Muhammad LJ, Algehyne EA, Usman SS, Ahmad A, Chakraborty C, Mohammed IA. (2021) Supervised machine learning models for prediction of COVID-19 infection using epidemiology dataset. SN computer Science 2(1):1-13.

Palaz F, Kalkan AK, Tozluyurt A, Ozsoz M. (2021) CRISPR-based tools: Alternative methods for the diagnosis of COVID-19. Clinical Biochemistry 89:1.

Polikar R. (2012) Ensemble learning. Ensemble machine learning, Springer, Boston, MA.

Rasheed J, Hameed AA, Djeddi C, Jamil A, Al-Turjman F. (2021) A machine learning-based framework for diagnosis of COVID-19 from chest X-ray images. Interdisciplinary Sciences: Computational Life Sciences 13(1):103-117.

Rish I. (2001) An empirical study of the naive Bayes classifier. In IJCAI 2001 workshop on empirical methods in artificial intelligence 3(22): 41-46. 
Tar E, Küçükoğlu S. (2021) COVID-19 ve Yenidoğan Sağlığı. N. Ulutaşdemir, İ. Kahriman (Ed), COVID-19 Pandemisinde Çocuk Sağlı̆̆1 içinde, https://iksadyayinevi.com/wpcontent/uploads/2021/05/COVID-19-PANDEMISINDE-COCUK-SAGLIGI.pdf

Worldometer (2021) COVID-19 Coronavirus Pandemic. https://www.worldometers.info/coronavirus/ Accessed 07.08.2021

Zimmermann P, Curtis N. (2020) Coronavirus infections in children including COVID-19: An overview of the epidemiology, clinical features, diagnosis, treatment and prevention options in children. Pediatr Infect Dis J. 39(5):355- 368. 